\title{
Phase Change Materials for Thermal Energy Storage
}

\author{
Mohammed Jafer Ali AL-Ataby \\ Collage of Engineering, AL-Mustansaryah University
}

Abstract:

Salt hydrate phase change materials used for thermal storage in space heating and cooling applications have low material costs, but high packaging costs. A more economic installed storage may be possible with medium priced, high latent heat. Latent heat storage is one of the most efficient ways of storing thermal energy. Unlike the sensible heat storage method, the latent heat storage method provides much higher storage density, with a smaller temperature difference between storing and releasing heat. This paper work on latent heat storage and provides an insight to recent efforts to develop new classes of phase change materials (PCMs) for use in energy storage. There are large numbers of phase change materials that melt and solidify at a wide range of temperatures, making them attractive in a number of applications. Hydrated salts have larger energy storage density and higher thermal conductivity but experience super cooling and phase segregation, and hence, their application requires the use of some nucleating and thickening agents. Sodium carbonate, sodium phosphate and sodium sulfate tested as phase change material by crystallization in this work.

Key words;, crystallization, salt hydrate, thermal energy, phase change material. 


\section{الخلاصة:}

تستخدم الأملاح المهدرجة كمواد متغيرة

الأطوار للخزن الحراري في مجال تطبيقات

التدفئة والتبريد لكونها مواد ذات كلف قليله

،لكنها مكلفه عند التعبئة فقط . الأملاح

المهررجة لها القابلية على العمل كوسط لخزن

الحرارة في بلور اتها كحر ارة (طاقه) كامنة ،

خزن الحرارة كحرارة كامنة تعتبر واحده من

أكفأ الطرق في خزن الطاقة الحرارية ،الأمر

غير المرغوب في طرق الخزن الحراري هذه أنها تعطي كثافة خزين عاليه جدا بتغير قليل في درجة الحرارة بين الخازن والباعث للحرارة .يدرس هذا البحث خزن الطاقة الكامنة وهو يعطي أصناف جديدة ومتطورة من المواد متغيرة الأطوار و التي تستعمل في خزن الطاقة ، حيث توجد أعداد كبيره من المواد متغيرة الأطوار والتي تتصهر وتتصلب في مدى واسع جدا من درجات الحرارة مما يجعلها ذات تطبيقات واسعة. الأملاح المهدرجة تمنلك كثافة خزن حراري عاليه جدا ولها خاصية التوصيل الحراري العالية ، لكن توجد مشكلة التبريد المتسرع وفصل الأطوار ، لهذا فان التطبيقات لهذه المواد تحتاج إلى إيجاد المواد المناسبة المضافة كعوامل مساعده لتثخين المحلول وبداية تكوين النوبات . في هذا البحث اختبرت كربونات الصوديوم، فوسفات
الصوديوم وكبريتات الصوديوم كمو اد متغيرة الأطوار للخزن الحر اري بعملية التبلور.

\section{Introduction:}

Today, classic cooling systems are used for room cooling, and these ensure that the rooms are cooled to a comfortable temperature in all environment climates. These systems are effective, however they would be a lot more energy-efficient if they used the natural temperature differences between day and night for cooling purposes. The use of the building mass as a storage medium is well known. This concept of night-time cooling has already been successfully implemented in many construction projects. The application of PCMs in buildings can have two different goals. First, the PCMs can be used to utilize natural heat and cold sources. For instance, solar energy for heating during the evening/night or the use of night cold for cooling during the day. Second, PCMs can use 
manmade heat or cold sources. In addition, different ways of using PCMs are available. In buildings, these again fall into two groups. PCMs can be located in building components such as walls or ceilings, or can be arranged in separate heat or cold stores. Using PCMs within buildings components are generally passive systems. The heat or cold is stored automatically and released when indoor or outdoor temperatures rise or fall beyond the phase change point of the material. Using PCMs in separate heat or cold stores are usually based on active systems. The stored heat or cold is in containment separated from the building itself and heat or cold transfer is not automatic, but used on demand.[1]

Crystallization is an important operation in the chemical industry , as a method of purification and a method of providing crystalline materials in the desired size range - In a crystal the constituent molecules, ion or atoms are arranged in a regular manner with the result that the crystal shape is independent of size , and if a crystal grows, each of the faces develops in a regular manner. The presence of impurities will, however, usually result in the formation of an irregular crystal . Generally large regular crystals are a guarantee of the purity of the material .Though a number of pairs of materials from "'mixed crystal". In recent years considerable development has taken place in techniques for growing perfect single crystals which are used in the production of semiconductor devices, laser beams , and artificial gems .....

The crystallization process consists essentially of two stages which generally proceed simultaneously but which can to some extent be independently controlled. The first stage is the formation of small particles or nuclei, and the second stage is the growth of the nuclei. If the number of nuclei can be controlled, the 
size of the crystals ultimately formed can be regulated. [2]

\section{Theoretical Aspects}

\section{Saturation:}

If melt is slowly cooled, the temperature will gradually fall until the melting point is reached and further cooling will then produce, either super-cooling of the liquid, or solidification with the temperature remaining approximately constant. Generally a definite degree of super-cooling must be achieved before change of phase will occur, and a meta stable condition therefore exists at temperatures a little below the melting point because the rate of spontaneous nucleation is here negligible. On the other hand, if a small seed crystal or other nucleus is introduced, it will increase in size until the solution is no longer super cooled.[2]

\section{Nucleation:}

Nuclei may form spontaneously if conditions are suitable, but in many cases small seed crystals may be added and small quantities of impurities may also act as nuclei. Spontaneous nucleation is a process which takes place with some reluctance and is thought to depend upon the existence of random variations in concentration or temperature on the molecular scale.

\section{Crystallization Rate :}

The rate of growth of crystal in a solution is dependent on the temperature and concentration of the liquid at the crystal face. These condition are not generally the same as those in the bulk of the solution because a concentration gradient is necessary for the transfer of solute towards the face, and a temperature gradient for the dissipation of the heat of crystallization. The problem thus involves both heat transfer and mass transfer, though in most 
cases the heat transfer may be negligible. In the case of melts, the problem is one of heat transfer alone. Since the resistance to heat and mass transfer lies predominantly in the laminar sub-layer close to the surface of the crystal, the rate of growth of the crystal is improved by increasing the relative velocity between the solid and the liquid. [2]

\section{Nucleation and Growth :}

It is clear that no discussion of a crystallizing system can be meaningful until the combined effects of nucleation rate, growth rate, heat balance, and material balance can be combined into a single equation. Theoretical analysis of nucleation and crystal growth is the subject of a large amount of literature. Tammann (1925) discussed the theory of nucleation and crystal growth, and outlined the various parameters involved in terms of, a probabilistic model involving a functional relation to pressure, temperature, and time. Many later studies deal with the nucleation and growth of crystals on an atomistic level. Although such studies a revere significant data on nucleation and crystal-growth kinetics are required for the system under study prior to development of atomistic models. Quantitative data on nucleation and crystal growth are available for only a few systems of geological importance, and the purpose of this section is to present a brief introduction to theories of nucleation and crystal growth as a prelude to the results of crystal-growth experiments. Nucleation involves the addition of atoms or molecules to a nucleus having the structure of the solid. If the nucleus is larger than a certain critical size, it will grow spontaneously, but if it is smaller than the critical size, the nucleus will be unstable. Critical size is dependent upon the amount of under cooling $[\Delta \mathrm{T}=\mathrm{T}$ (liquidus)$\mathrm{T}$ (growth)] and varies from an 
infinite size at liquidus temperatures to smaller sizes at greater degrees of under cooling. Another factor in the nucleation of crystals from a melt is the mobility of atoms and molecules in the melt as measured by the diffusion coefficient. As the temperature drops below the liquidus, nucleation will increase from zero to a maximum at some under cooling. Diffusion rates are then very low and nucleation decreases with further decrease in temperature. This explains the pattern of nucleation in liquids where the liquid diffusivity decreases with temperature. Crystal growth from a melt proceeds by attachment of chemical species from the liquid to the crystal nuclei. Rate of growth is thus a function of mobility of crystal-forming species within the melt. Mobility, as measured by the diffusion coefficient, drops with decreasing temperature, and growth rate, like nucleation, is expected to rise from zero at the liquidus to a maximum at some under cooling and then decrease. This is the expected pattern of growth rate of crystals from a viscous liquid. [3]

\section{Crystals :}

A crystal may be defined as a solid composed of atoms arranged in an orderly repetitive array. The inter atomic distances in a crystal of any definite material are constant and are characteristic of that material . Because the pattern or arrangement of the atoms is repeated in all directions, there are definite restriction on the kinds of symmetry that crystals can possess . [2]

\section{Heat Effects In a Crystallization}

\section{Process:}

The heat effects in a crystallization process can be computed by two methods:-

1-A heat balance can be made where in the individual heat effects such as sensible heats, latent heats, and the heat of crystallization can be combined into an equation for the total heat 
effects: or,2-An enthalpy balance can be made in which the total enthalpy of all leaving streams minus the total enthalpy of all entering streams is equal to the heat absorbed from external sources by the process. In using the heat-balance method, it is necessary to make a corresponding mass balance, since the heat effects are related to the quantities of solids produced through the heat of crystallization .With compounds whose solubility increases with increasing temperature there is an absorption of heat when the compound dissolves which is called the heat of solution . In compounds with decreasing solubility, as the temperature increases there is an evolution of heat when solution occurs.

When there is no change in solubility with temperature there is no heat effect . The solubility curve will be continuous as long as the solid substance of a given phase is in contact with the solution, and any sudden change in the slope of the curve will be accompanied by a change in the heat of solution and a change in the solid phase .

Heats of solution are generally reported as the change in enthalpy associated with the dissolution of large quantity of solute in an excess of pure solvent . At equilibrium the heat of crystalllization is equal and opposite in sign to the heat of solution using the heat of solution at infinity dilution as equal, but opposite in sign to the heat of crystallization is equivalent to neglecting the heat of dilution. With many materials the heat of dilution is small in comparison with the heat of solution and the approximation is justified ,however, there are some exception . Relatively large heat effects are usually found in the crystallization of hydrated salts . In such cases the total heat released by this effect may be a substantial portion of the total heat effects in a cooling-type crystallizer . In evaporation -type 
crystallizers the heat of crystallization is usually negligible when compared with the heat of vaporizing the solvent .[4]

\section{Thermo chemical heat storage:}

An important contribution to sustainable energy is an efficient use of solar heat and industrial waste heat. Storage of energy is an important issue in this context. Traditional sensible heat storage techniques offer a number of disadvantages. Substantial heat loss and relatively low energy density are the most serious drawbacks. An alternative to heat storage in water tanks is the thermo chemical heat storage utilizing reversible physical chemical processes offering the advantage of high energy density and very low energy losses. The sorption-desorption equilibrium of water vapor in micro porous materials such as zeolithes is one such example. More recently, research has been conducted in the use of chemical reactions such as hydration-dehydration reactions of metal salts for the thermo chemical storage of energy.[5]

The use of salt hydrates in a thermo chemical system is based on the release of the heat of hydration. Hence, a salt hydrate storage system is charged by the endothermic thermal dehydration of the respective higher hydrated salt. Many salts can be dehydrated at temperatures that can well be achieved using solar thermal collectors. In this state, the energy can be stored over long periods of time implying its application for seasonal storage. The exothermic back reaction may be initiated by simply increasing the water vapor partial pressure. The performance of a salt hydrate storage system largely depends on the kinetics of the hydration and dehydration reactions. The objectives of our research are as follows:

Selection of appropriate metal salts based on their thermodynamic properties and the kinetics of the respective 
hydration and dehydration reactions. (2) Testing of different porous substrates including meso porous materials for the salt hydrate [6]

\section{Experimental work :}

The experimental work complete in the chemical engineer department laboratory by using hydrated salts as thermal energy storage material like \{sodium carbonate decahydrate (Na2CO3.10H2O), sodium phosphate dodechaydrate (Na2HPO4 $.12 \mathrm{H} 2 \mathrm{O}$ ) , and sodium sulfate decahydrate (Na2SO4.10H2O), a pure and analytical material was used in this work (Merck Germany). The procedure for these experiments by pass cooling air through hydrated salt solution putted in the (2L) glass container, on this container fixed thermometer to measuring the temperature .The cooling air agitated the solution by bubbling in constant velocity and temperature ,every (5 minutes ) record the thermometer temperature (temperature of the system ) .Fig(1) refer to the experimental rig which this research tests done by it, it consists the parts coded from one (1) to fourteen (14) as shown in figure. 


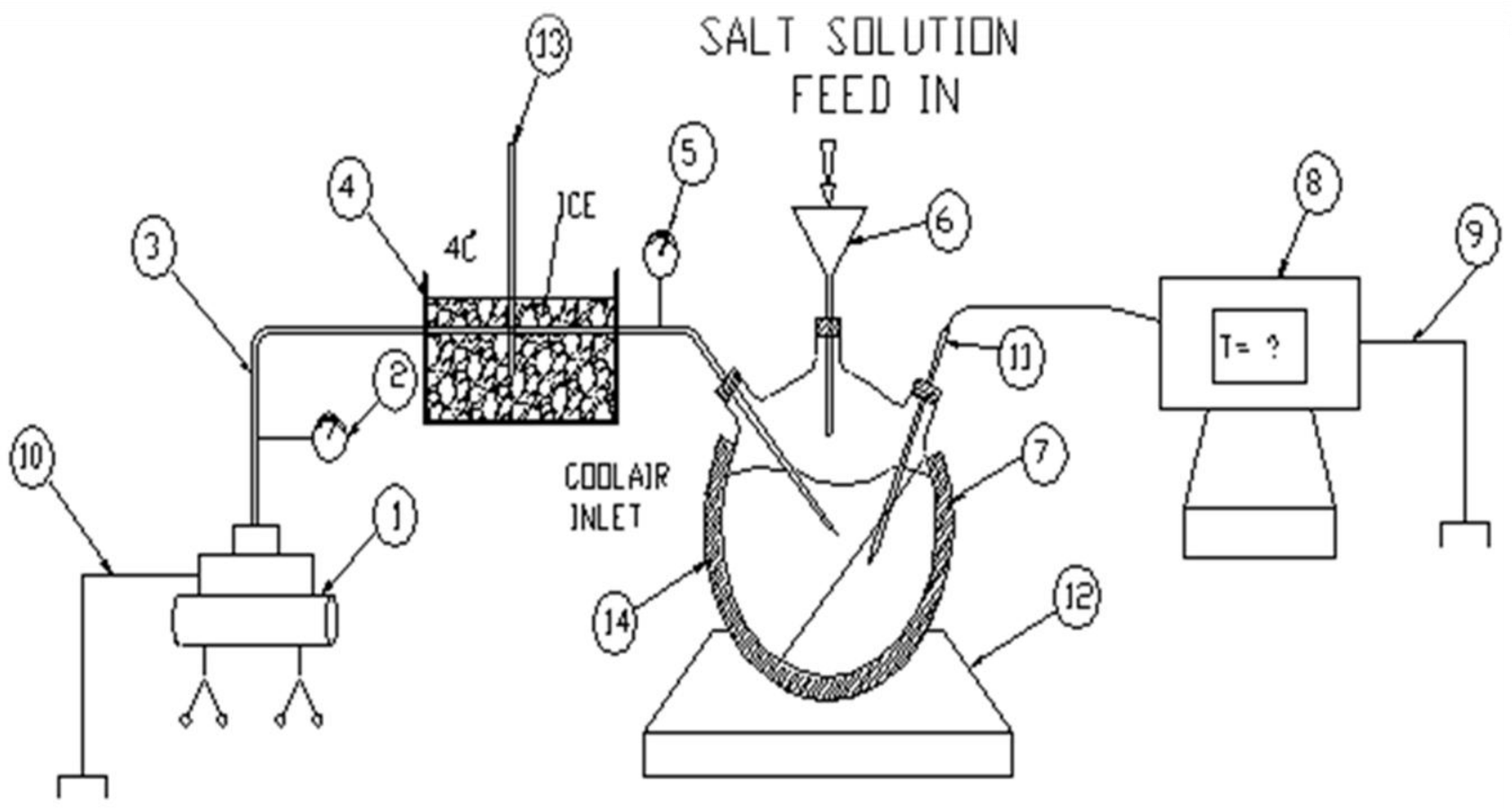

Fig..(1 ) Experimental rig for the experimental work
(1)- Air-Compressor ,
(2)- Air-flow indicator ,
(3)- Copper pipe ,
(4)- Ice container, (5)- Temperature indicator , (6)- Funnel, (7)- Conical flax (2L), (8)- Temperature indicator, (9\&10)- Electrical connection , (11)- Thermocouple, (12)-Bench , (13)- Thermometer (14)-Insulators 


\section{The Result:}

There are many experiments done to study the crystallization rate of these hydrated salts ,but selected the best tow results of the experiments for each state of the following salts and plot its as in Fig(3,5and7) respectively :

\section{1) Sodium Carbonate Decah-} ydrate

\section{( Na2CO3.10H2O ) :}

Which is commonly known as washing soda. The decahydrate contains $37 \%$ sodium carbonate and $63 \%$ water. It forms several salt hydrates with different crystal habits . The decahydrate changes to heptahydrateat $\left(32^{\circ} \mathrm{C}\right)$ and to monohydrate at $\left(36^{\circ} \mathrm{C}\right)$, this dissolves almost completely. The material must be nucleation to form decahydrate crystals and formation of the heptahydrate must be avoided. Sodium carbonate is one of the least expensive and most available chemical. It is produced in large quantities from such natural sources as salt lakes and dry deposits . Sodium carbonate decahydrate melts at $\left(32{ }^{\circ} \mathrm{C}\right)$, Sodium carbonate decahydrate is a good candidate for the storage of solar energy. Although its melting point, at $\left(32^{\circ} \mathrm{C}\right)$, is some what on the low side, its relatively high heat of fusion of $(247 \mathrm{kj} / \mathrm{kg})$ is definite advantage.[7]

For this material at transition temperature $500 \mathrm{gm}$ of sodium carbonate dissolved in (1L) of water, fixed the temperature of cooling air for bubbling at $15^{\circ} \mathrm{C}$. This solution being saturated with sodium carbonate at the transition temperature and nucleation from glass container can observe, no problem in nuclei contained. Crystallization started invariably when the bubbling cooling air maintained the temperature inside the glass container $(29-30)^{\circ} \mathrm{C}$. The cooling cycles could be carried out with such sealed container without any appreciable under cooling .Fig.(2) represented the diagram 
of $\quad 37 \%$ sodium carbonate

solubility in water vs the

temperature, fig(3) show the

(time-temperature) curve of

experiment which represented the

crystallization process of this state.

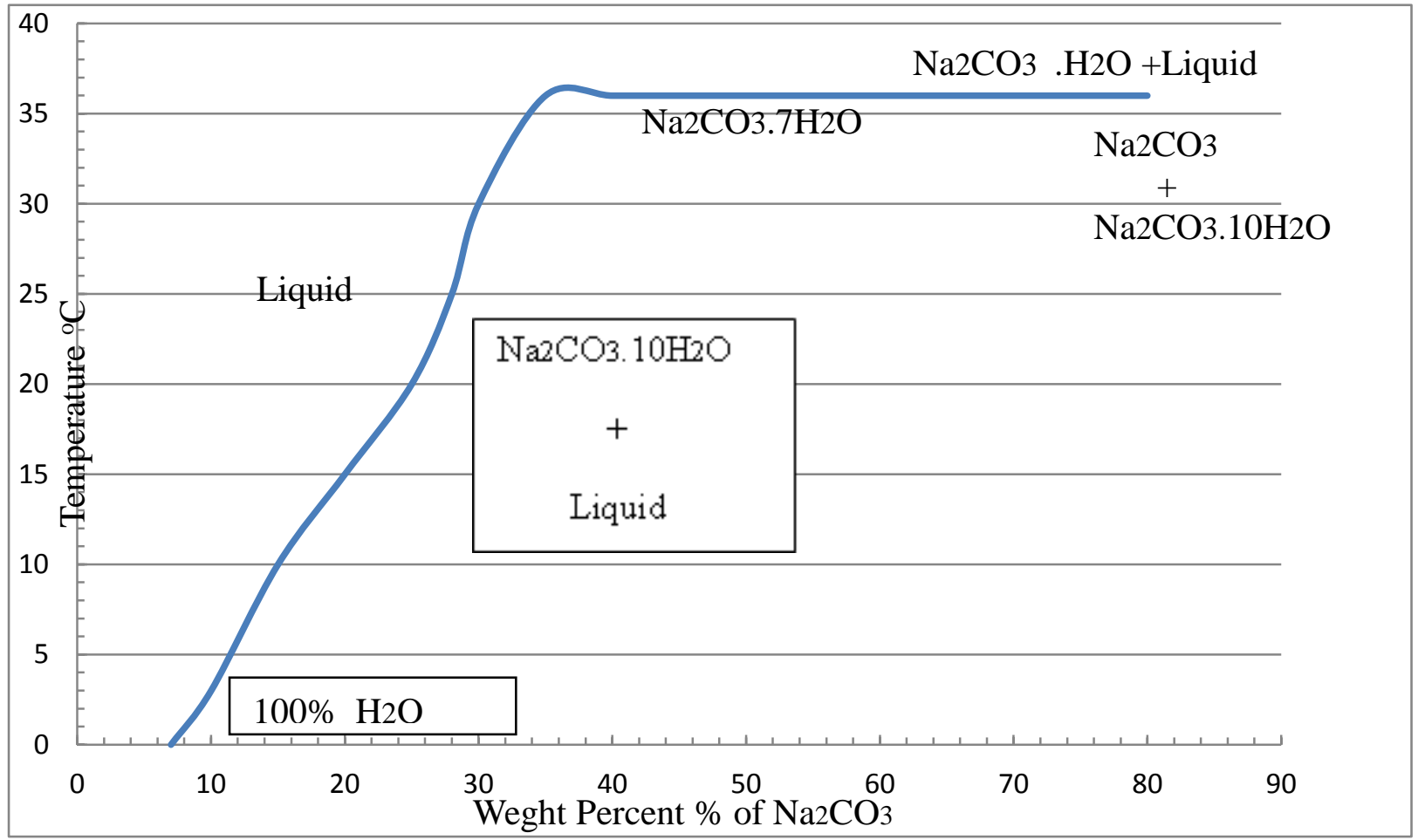

Fig..(2) Phase Diagram Of Sodium Carbonate-Water System (Solubillity Diagram)[10] 


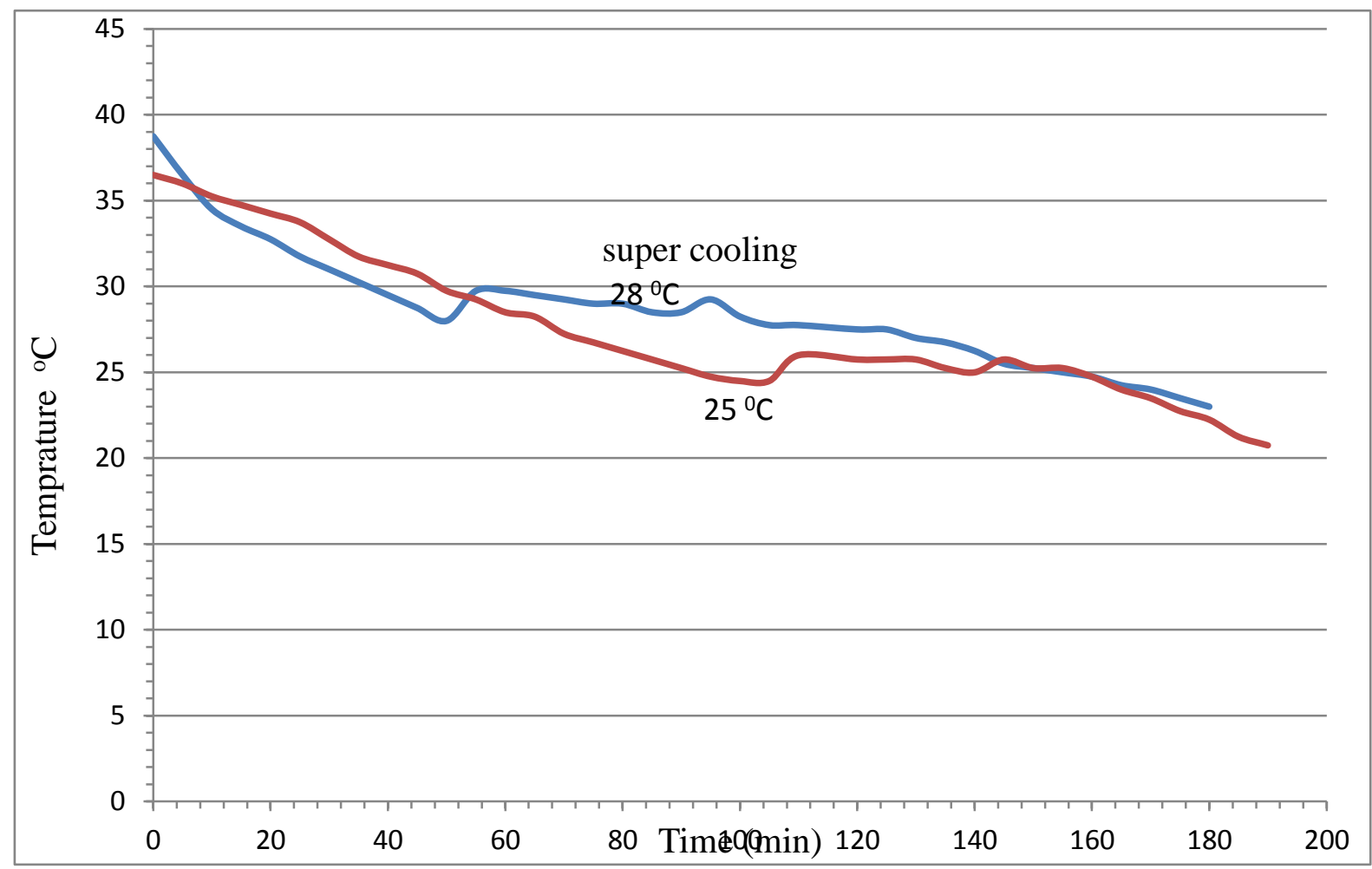

Fig. ( 3 ) Cooling curves of Sodium Carbonate Deca-hydrate

2)Soduim Phosphate Dodechydrate (( Na2HPO4 .12H2O) :

has been subjected to 90 consecutive cycles, without any noticeable change. The material must be prepared and used in combination with a nucleating system. disodium phosphate dodechydrate contains $42 \%$ sodium phosphate and58\%water, melts at $\left(36^{\circ} \mathrm{C}\right)$, disodium phosphate dodechydrate is a good candidate for the storage of solar energy. Although its melting point, at $\left(36^{\circ} \mathrm{C}\right)$, is some what on the low side, its relatively high heat of fusion of $(265.6 \mathrm{kj} \backslash \mathrm{kg})$ is definite advantage.[8]. For this material at transition temperature $530 \mathrm{gm}$ of sodium phosphate dissolved in (1L) of water, fixed the temperature of cooling air for bubbling at $15^{\circ} \mathrm{C}$. This solution being saturated with sodium phosphate at the transition temperature and nucleation from glass container can observe, no problem in nuclei contained. 
crystallization started invariably when the bubbling cooling air maintained the temperature inside the glass container $\left(32^{\circ} \mathrm{C}\right)$. The cooling cycles could be carried out with such sealed container without any appreciable under cooling . Fig.(4) represented the diagram of $42 \%$ sodium phosphate solubility in water vs the temperature, $\operatorname{fig}(5)$ show the (time-temperature) curve of the experiment which repressented the crystallization process of this state . using disodium phosphate dodeca-hydrate as a phase change material and air as a heat transfer fluid, bubbled through the salt solution. The agitation caused by the bubbles reduced both the sub-cooling and phase segregation the two problem associated with crystallization of most hydrated salts .[9] 


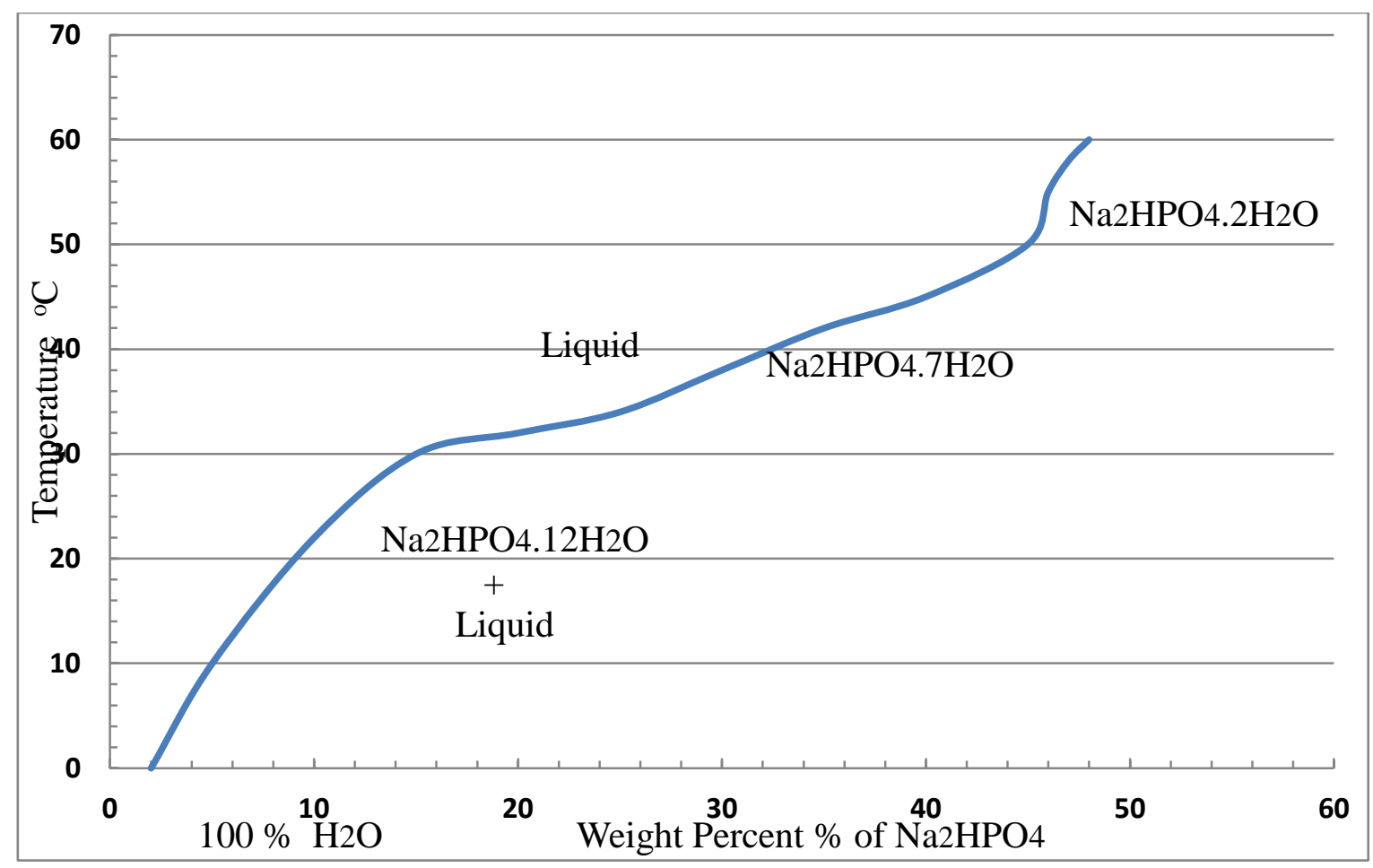

Fig.(4) Phase Diagram Of Sodium Phosphate -Water System (Solubillity Diagram)[10]

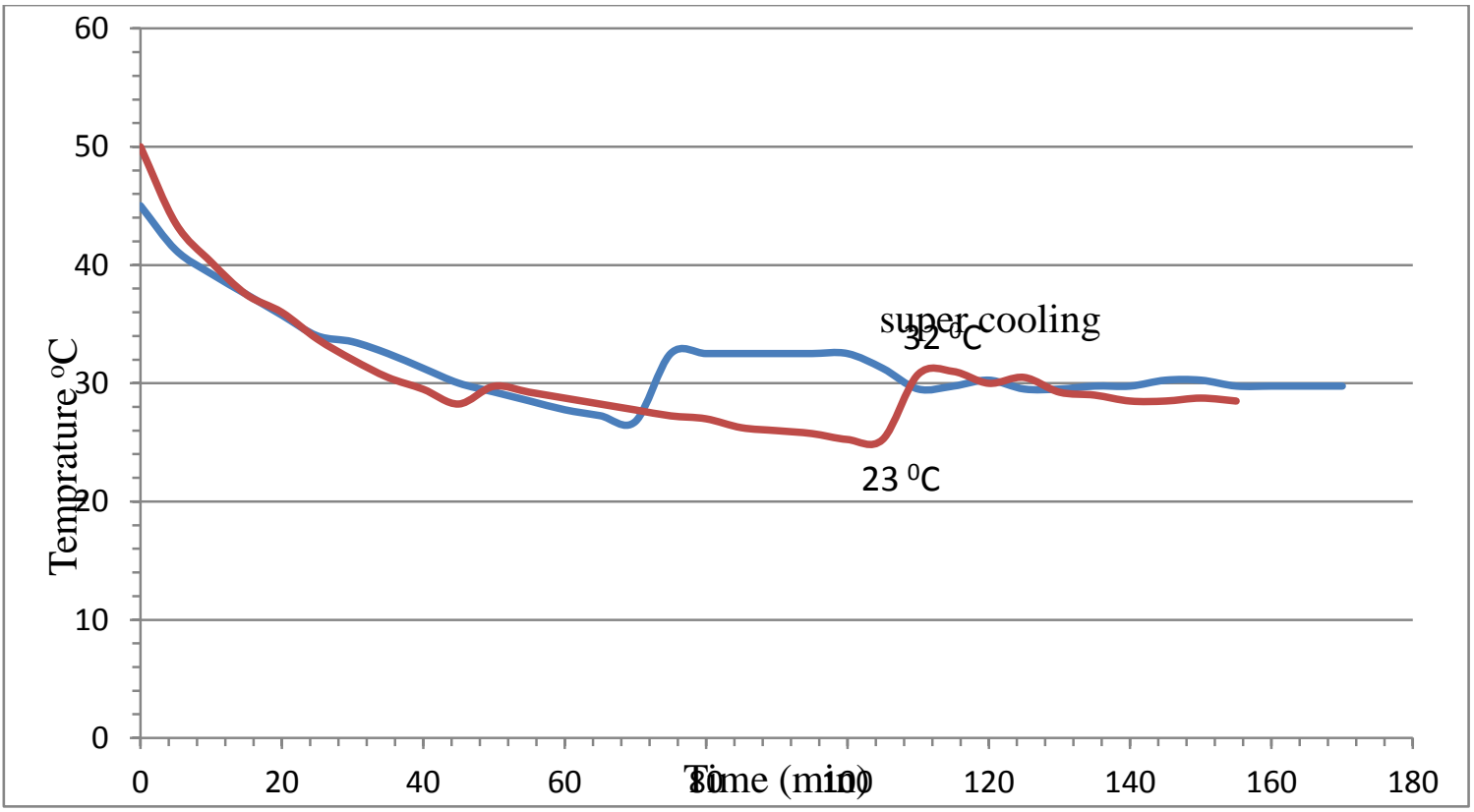

Fig. ( 5 ) Cooling curves of Sodium phosphate dodechydrate 
3)Sodium Sulfate Decahydrate

(Na2SO4.10H2O) :

is one of the least expensive and most available chemical. It is produced in large quantities as a by product of several processes and can also be obtained from such natural sources as salt lakes and dry deposits. Sodium sulfate decahydrate which contains $44 \%$ $\mathrm{Na} 2 \mathrm{SO} 4$ and $56 \% \mathrm{H} 2 \mathrm{O}$, melts at ( $31.5^{\circ} \mathrm{C}$ ), when it partly dissolves in the available water leaving some solid residue . Being heavier, the residue settles to the bottom of the container. If the material is stirred occasionally, total crystallization is obtained, without separation, residue or uncombined liquid . Sodium sulfate decahydrate is a good candidate for the storage of solar energy . Although its melting point, at $\left(31.5^{\circ} \mathrm{C}\right)$ is somewhat on the low side, its relatively high heat of fusion of $(251.6 \mathrm{kj} \mathrm{kg})$ is a definite advantage. [6]
There are many experiment done to phase change of sodium sulfate decahydrate Noticed that the nucleation of this material is difficult , therefore, it was necessary to find a nucleation catalyst in this specification (slightly soluble in super saturated solution of sodium sulfate to avoid depression of the transition temperature, the best catalyst that increased in solubility at higher temperatures, dissolving as the sodium sulfate was heated above its transition temperature and crystallizing again as the super saturated solution was cooled, forming a large number of nuclei for the $\mathrm{Na} 2 \mathrm{SO} 4.10 \mathrm{H} 2 \mathrm{O}$ crystals ). From many literature take many catalyst like sodium tetra borate decahydrate ,borax . [11] When 3 to $4 \%$ borax is added to sodium sulfate decahydrate its melting point decreases slightly to $31.5^{\circ} \mathrm{C}$, but super cooling is eliminated and the material invariably starts crystallizing at 83 to $85^{\circ} \mathrm{C}$. For this woke was added sodium tetra 
borate decahydrate, the nucleation could be performed in the glass container .The relatively slight solubility of sodium tetra borate in water is further decreased by the presence of sodium sulfate in solution .[20]

The transition temperature of the equilibrium mixture is decreased slightly ,from 34.5 to $31.5^{\circ} \mathrm{C}$.At the transition temperature (490gm) of sodium sulfate and $(20.5 \mathrm{gm})$ of sodium tetra borate dissolve in (1L)of water, without the presence of sodium tetra borate the solubility of sodium sulfate is (510gm), which may increase to (540gm)in the supersaturated, under cooling state. This soluteion being saturated with sodium sulfate and sodium tetra borate at the transition temperature and nucleation from glass container can observe, crystallization started invariably when the bubbling cooling air maintained the temperature inside the glass container $\left(30^{\circ} \mathrm{C}\right)$. The cooling cycles could be carried out with such sealed container without any appreciable under cooling .Fig(6) represented the diagram of $44 \%$ sodium sulfate solubility in water vs the temperature, fig(7) show the(time-temperature) curve of the experiment which represented the crystallization process of this state 


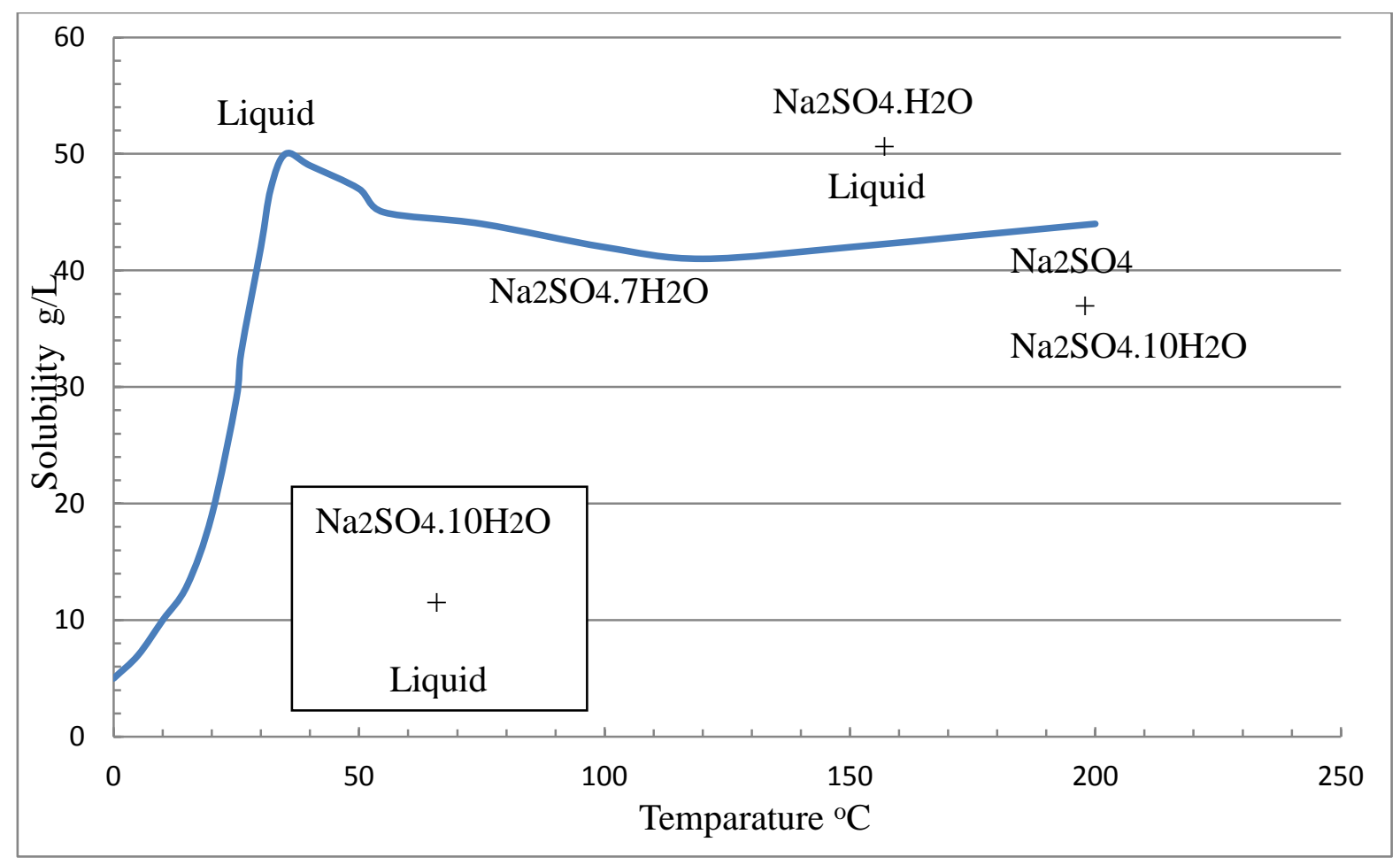

Fig.(6) Phase Diagram Of Sodium Sulfate -Water System (Solubillity Diagram) [10]

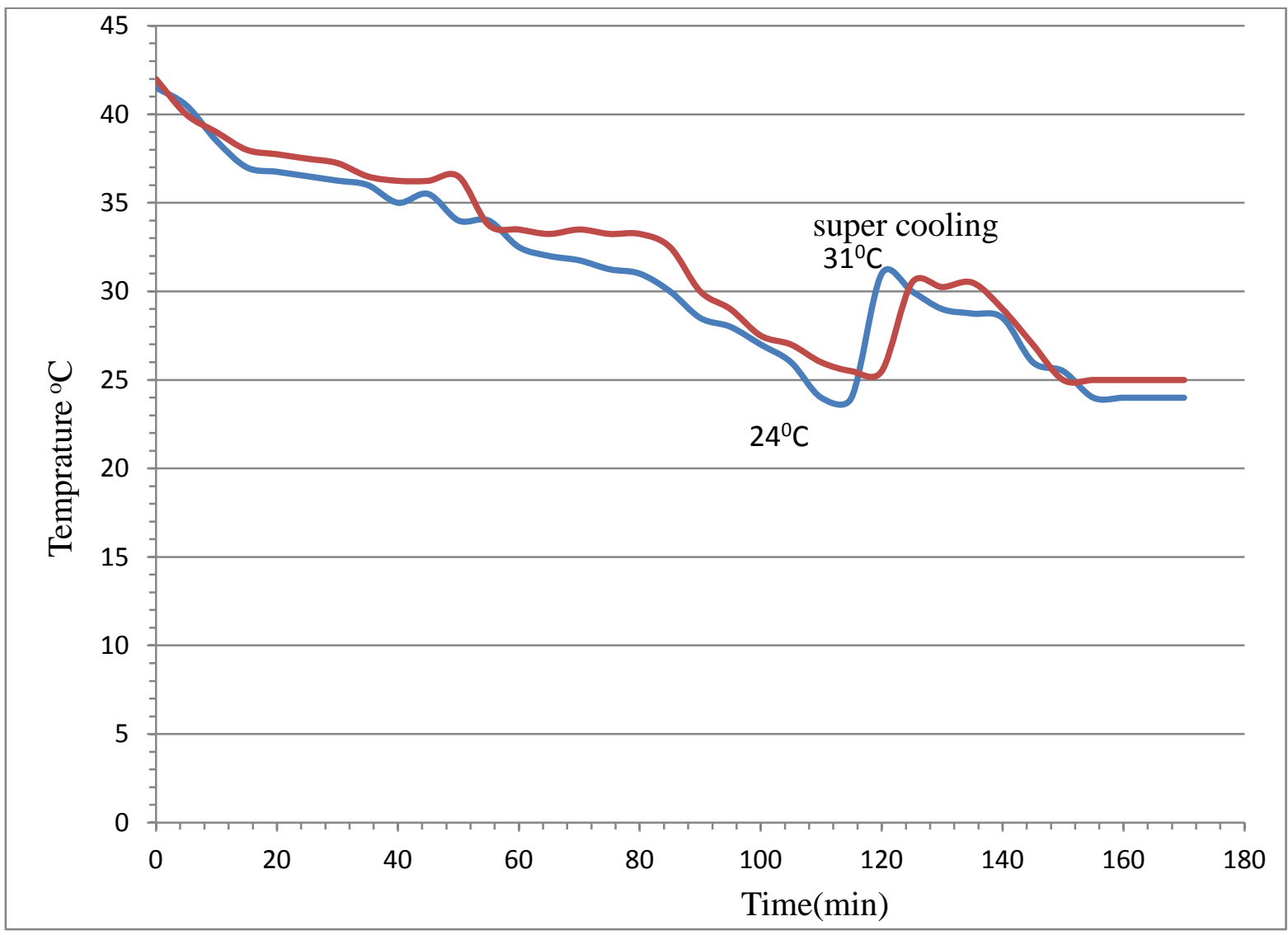

Fig.( 7 ) Cooling curves of Sodium Sulfate Decahydrate 
Discussion :

Most hydrates show a strong tendency to super cooling. This implies that in the phase of discharging the heat of fusion cannot be extracted at the melting point but only at temperature several degrees lower at which spontaneous crystallization occurs .The degree of super cooling is more or less random and influenced effects such as impurities ,it may be reduced or even decreased to zero by adding solid material which initiates the crystallization .Such nucleation may be caused, for example , by crystals of a material which resembles the storage medium in structure and lattice parameters but which does not dissolve at operational temperatures.[12]

Table( 1 ). show the properties and cost of the hydrate salts [13]

\begin{tabular}{|c|c|c|c|c|c|c|c|}
\hline \multirow[t]{3}{*}{ hydrate Salt } & Water & Melting & Heat of & Density & $\$ \backslash 100$ & $\mathrm{kj} \backslash \$$ & \multirow{3}{*}{$\begin{array}{r}\text { Cost of } \\
\text { storage } \\
\text { kj.\$}\end{array}$} \\
\hline & \multirow[t]{2}{*}{ Mols } & Point $\quad{ }^{\circ}$ & Fusion & $\mathrm{kg} \backslash \mathrm{m}^{3}$ & $\mathrm{~kg}$ & & \\
\hline & & C) & kjlkg & & & & \\
\hline Sodium & \multirow[t]{2}{*}{10} & \multirow[t]{2}{*}{$32-36$} & \multirow[t]{2}{*}{247} & \multirow[t]{2}{*}{1361} & \multirow[t]{2}{*}{4.41} & 5591.5 & \multirow[t]{2}{*}{200.5} \\
\hline Carbonate & & & & & & & \\
\hline Sodium & \multirow[t]{2}{*}{12} & \multirow[t]{2}{*}{36} & \multirow[t]{2}{*}{265.6} & \multirow[t]{2}{*}{1436} & \multirow[t]{2}{*}{15.43} & 1688 & \multirow[t]{2}{*}{548.6} \\
\hline Phosphate & & & & & & & \\
\hline Sodium & \multirow[t]{2}{*}{10} & \multirow[t]{2}{*}{$30-32$} & \multirow[t]{2}{*}{251.6} & \multirow[t]{2}{*}{1467} & \multirow[t]{2}{*}{2.65} & \multirow[t]{2}{*}{9495} & \multirow[t]{2}{*}{116} \\
\hline Sulfate & & & & & & & \\
\hline
\end{tabular}


The hydrate salts described above are compared on the basis of raw material costs in above table. Heat content costs $(\mathrm{kj} / \$)$, and costs per 1 million $\mathrm{kj}$ storage. From the table (1) show that sodium sulfate decahydrate has the lowest raw material cost . Sodium carbonate decahydrate is inexpensive but its nucleation has not been established and it is also extremely corrosive [13]. Sodium phosphate dedecahydrate with its higher melting point of $36 \mathrm{~F}^{\circ}$ may appear desirable, but at an increased cost. The prices in this table are for food grade and photo grade salts, less expensive technical grades .Direct contact heat transfer with phase change using hydrated salts provides very high heat transfer rates [14]. The high volumetric heat transfer coefficient, which can be achieved in such a system, is mainly due to the large surface area of the droplets of the immiscible heat transfer fluid used to transfer the heat from or to the heat storage unit [15].
The high latent heat of crystallization of most hydrated salts compensates for the extra water used to avoid precipitation of the an hydrous salt.[16]

From the figures(1,2and3) respectively can noticed that the hydrated salts which used in these experiments was a good material in nucleation and growth of crystal when the temperature decreases ,but, in decahydrate sodium sulfate state the salt solution needed to catalyst for enhanced the formation of nuclei. The problem of super cooling can observe in fig.(1) between $(25-28)^{\circ} \mathrm{C}$, from fig.(2) super cooling between (23$32)^{\circ} \mathrm{C}$ and for fig.(3) super cooling between $(24-31)^{\circ} \mathrm{C}$. That mean the melting state returned to liquid phase and needed more time to back the system to the melting state, the reason of all these in the above experiments come from the velocity and temperature of air that used in bubbling the system not fixed ,and the container effected by the ambient 
temperature ,thus must isolated it to get best resulted .Super cooling affect on the energy storage in the crystals, because its draw out some of the energy at form of heat and decreases the amount of energy storage. From fig. (2), (4)and (6) noticed the solubility diagram of $37 \%$ sodium carbonate, $42 \%$ sodium phosphate and $44 \%$ sodium sulfate in water vs the temperature respectively, that show the saturated state of these salts and can detected the weight percent of the salt solution converted to solid phase at any temperature of the system multiplied this value by percent of molecular weight of $(\mathrm{Na} 2 \mathrm{CO} 3)$ to the molecular weight of $(\mathrm{Na} 2 \mathrm{CO} 3.10 \mathrm{H} 2 \mathrm{O})$, and the same way for sodium phosphate, and sodium sulfate. [17]

Hydrated salts are attractive materials for use in thermal energy storage due to high volumetric storage density, relatively high thermal conductivity and moderate costs compared to organic material like paraffin waxes [18]. The selection of such material as PCM for a specific application should be based on thermodynamic properties, kinetic properties and chemical properties. For low temperature applications ranging from $0^{\circ} \mathrm{C}$ to $99^{\circ} \mathrm{C}$, Salt Hydrates would be the best option owing to their availability in a less temperature range with a reasonable specific heat capacity of $\quad 0.56(\mathrm{kj} / \mathrm{deg} . \mathrm{mol}), \quad$ thermal conductivity of $0.987 \mathrm{~W} / \mathrm{m}-\mathrm{K}$, density of $1552 \mathrm{~kg} / \mathrm{m} 3$ in the solid phases respectively and phase transfer temperature ranging from $35^{\circ} \mathrm{C}-39^{\circ} \mathrm{C} .[19]$

\section{Conclusions:}

Inorganic compounds have a high latent heat per unit volume and high thermal conductivity and are non-flammable and low in cost in comparison to organic compounds .However, they are corrosive to most metals and suffer from decomposition and sub cooling, which can affect their 
phase change properties. The applications of inorganic PCMs require the use of nucleating and thickening agents to minimize sub cooling and phase segregation. Significant efforts are continuing to discover those agents by commercial companies. The applications in which PCMs can be applied are vast, ranging from heat and coolness storage in buildings to thermal storage in satellites and protective clothing. A PCM with an easily adjustable melting point would be a necessity as the melting point is the most important criterion for selecting a PCM for passive solar applications. Many more applications are yet to be discovered.

\section{List Of Symbols:}

PCMs ; phase change materials

$\mathrm{kg}$; kilograms

kj ; kilojoules

W ; watt

${ }^{0} \mathrm{C}$; degree centigrade

Min ; minutes

\$ ; dollar

$\mathrm{m}^{3} \quad$; cubic meter

deca ; ten (10)

dode ; twelve (12) 


\section{References:}

1. Abhat.A, "Low temperature latent heat thermal energy storage, Heat storage materials", Solar Energy; 30,pp.313-32, 1983.

2. Ryu, H.W., Woo, S.W., Shin, B.C. and Kim S.D., Prevention of Super cooling and Stabilization of Inorganic Salt Hydrates as Latent Heat Storage Materials. Solar Energy Materials and Solar Cells 27. 161-172. (1992).

3. Zalba, B., J. M. Marin, L. F. Cabeza, and H. Mehling. Review on thermal energy storage with phase change: Materials, heat transfer analysis, and applications. Appl. Ther. Eng. 23(3): 251-283,2003.

4. I. Dincer, M. A. Rosen , “Thermal energy storage, systems and applications", John Wiley and sons, chickaester (England)2002.

5. Belenzalba , Jose M. Marin, LusiFeabeza, Harald Mehling, "Review on Thermal energy storage with phase change materials, heat transfer analysis and application", Applied thermal eng g, pp.251-283,23(2003).

6. Xiao, M., Feng B. and Gong K., Preparation and Performance of Shape Stabilized Phase Change Thermal Storage Materials with High Thermal Conductivity. Energy Conversion and Management 43. 103-108. (2002).

7. Hawes DW, Feldman D, "Absorption of phase change materials in concrete”, Solar Energy Material and Solar Cells,Vol.27, pp.91-101, 1992.

8. Arkar C, Medved S, "Enhanced solarassisted building ventilation system Using sphere encapsulated PCM thermal heat storage”. IEA, ECES IA Annex 17,advanced thermal energy storage techniques-feasibility studies and demonstration projects $2^{\text {nd }}$ workshop; Ljubljana, Slovenia,3-5April 2002.

9. Stritih U, Novak P, "Thermal storage of solar energy in the wall for Building ventilation" Second workshop: IEA,ECESIA Annex 17, Advanced thermal energy storage techniques - feasibility studies and demonstration projects, Ljubljana, Slovenia. 3-5, April 2002.

10. Peippo K, Kauranen P, Lund PD, “A Multi component PCM wall optimized for passive solar heating”, Energy Building, Vol. 17, pp.259270,1991 . 
11. Feustel HE, Stetiu C, "Thermal performance of phase change wallboard for residential cooling application" Lawrence Berkeley National laboratory, Report LBL-38320,1997.

12. Neeper D, "Thermal dynamics of wallboard with latent heat storage", Sol Energy , 68, pp.393-403,2000.

13. Salyer IO, Sircar AK, "Phase change materials for heating and cooling of residential buildings and other applications" In: Proceedings of $25^{\text {th }}$ intersociety energy conversion engineering conference. pp.23643,1990.

14. Athienitis AK, Liu C, Hawes D, Banu D, Feldman D, “ Investigation of the Thermal performance of a passive solar test-room with wall latent heat storage" Building and Environment, 32,pp.405-10,1997.

15. Lee T, Hawes DW, Banu D, Feldman D, “ Control aspects of latent heat storage and recovery in concrete", Sol Energy Material and Solar Cells, 62,pp.217-37, 2000.

16. Hawes DW, Banu D, Feldman D, "Latent heat storage in concrete II", Solar Energy Materials, 21, pp.61-80, 1990.

17. Hadjieva M, Stoykov R, Filipova T," Composite salt-hydrate concrete System for building energy storage", Renewable Energy, 19,pp. 11-15, 2000.

18. Mehling R, Krippner A, Hauer," Research project on PCM in wood-light weight-concrete", In Proceedings of the second workshop of IEA ECES IA Annex.

19. Feldman, D., M. M. Shapiro, "Organic phase change materials for thermal energy storage." Solar Energy Materials 13: 1-10, et al. (1986).

20. Khudhair, A. M., and M. M. Farid. A review on energy conservation in building applications with thermal storage by latent heat using phase change materials. Energy Converse. Mgmt. 45(2):263-275, 2004. 